\title{
Política, religión y antiderechos en los debates por la Ley de IVE
}

Pablo Gudiño Bessone

CIS-IDES/CONICET/IAPCS-UNVM

Si la fecundidad es el lugar central de la dominación de lo masculino, la conquista por parte de las mujeres del control de su propia fecundidad, por lo tanto, se convierte para ellas en un medio de salir del lugar de la dominación.

Françoise Héritier, Masculino/Femenino II. Disolver la Jerarquía, 2007

El año 2018 fue clave en la Argentina, un año de movilizaciones y ocupación del espacio público; de ampliación del movimiento feminista en la identificación y protagonismo que las nuevas generaciones de jóvenes asumieron con la denominada "marea verde"; de luchas colectivas por la construcción de ciudadanía; y de interpelación al Estado por la legalización/despenalización del aborto en tanto derecho personal, colectivo, y como un problema de salud pública que devela situaciones de desigualdad estructural y de violencias institucionales. Por primera vez en la historia del país, el Proyecto de Ley de Interrupción Voluntaria del Embarazo (IVE) logró alcanzar tratamiento parlamentario, obteniendo media sanción en la Cámara de Diputados pero, finalmente, denegado por el Senado de la Nación. Cuestión, esta última, que evidencia un índice de fragilidad del Estado ante el poder de los sectores conservadores, además de un arraigo confesional de una mayoría de la dirigencia política argentina permeable a los intereses de la jerarquía eclesiástica en la definición de las legislaciones y de los sentidos de la normatividad jurídica.

Tras años de lucha, el movimiento feminista logró instalar el aborto en la opinión pública como un tema de Salud Pública y de vulnerabilidad de derechos. No obstante, el contexto de debate por la Ley de IVE trajo aparejada la presencia, en el espacio público, de sectores religiosos conservadores cuyo protagonismo y actuación también se habían hecho visibles en escenarios sociohistóricos anteriores, como lo fueron los debates por el divorcio, la ley de matrimonio igualitario, la anticoncepción y la educación sexual integral. Acorde con ello, el reciente y latente debate por la legalización del aborto en la Argentina dejó en claro los modos en que la inclusión en la agenda social y política de procesos de reconocimiento y de contienda de derechos por la ampliación de las libertades sexuales y (no)reproductivas provoca impactos sobre el campo de la religión, que se traducen en formas de politización de lo religioso ante una eminente politización de la sexualidad. 
El avance de los autodenominados grupos "pro-vida", en oposición al aborto y a la modificación y actualización de la Ley de Educación Sexual Integral (ESI), permite dar cuenta de la reacción que llevan adelante los sectores religiosos conservadores toda vez que se pone en discusión una defensa de la sexualidad vinculada al placer, a la autodeterminación del propio cuerpo, y separada del mandato de la maternidad y la procreación. Los grupos pro-vida son actores de la sociedad civil cuyo despliegue en la esfera pública obliga a complejizar los análisis del catolicismo en tanto movimiento e institución, y a comprender los nuevos rostros políticos que asumen las iglesias evangélicas en su oposición a los derechos sexuales y (no)reproductivos y en defensa de un modelo tradicional de familia y sexualidad. Ya sea en la Argentina como en América Latina y a nivel transnacional, tanto la Iglesia Católica como las iglesias evangélicas mantienen su enfrentamiento con las organizaciones feministas en el activismo político que asume su feligresía en el espacio público. Ello supone un esfuerzo investigativo por visibilizar los múltiples actores que intervienen y forman parte del espacio de la lucha antiabortista y, a la vez, comprender las particularidades que hacen al fenómeno social y político de emergencia de las organizaciones antiderechos y los modos en que estas resultan clave en el sostenimiento de una agenda conservadora, heteronormativa y desfavorable a la ampliación de la ciudadanía sexual.

Las alianzas entre actores católicos y evangélicos en contraposición a la Ley de IVE y articulados en espacios políticos como Unidad Provida permiten dar cuenta de los impactos que el movimiento feminista y la diversidad sexual generaron sobre el campo de lo religioso en términos de su reconfiguración, su reposicionamiento, su dinámica y desplazamiento de sentidos. Los actores religiosos son sujetos políticos que intervienen de manera activa en la arena democrática, mientras tanto, en los últimos tiempos, la proliferación de emergencia de colectivos y organizaciones "pro-vida" y "pro-familia" se ha convertido en una manifestación de cómo las propias religiones se van reinventando en la creación de núcleos de participación ciudadana que tienen por objetivo la defensa de una moral sexual religiosa enemistada con lo que autodenominan los riesgos de la "ideología de género".

En cuanto a los argumentos y narrativas que circularon en oposición a la Ley de IVE, se observa una fetichización de los fetos-embriones como personas jurídicas desde el instante de la concepción, jugando un papel importante la apelación al discurso biomédico, científico y legal. Dicho discurso - de imbricación entre lo religioso, lo científico y lo jurídico- tiene por objeto reforzar los embates punitivistas contra los derechos a la autonomía sexual y (no)reproductiva de las mujeres, e intentar crear lazos de empatía emocional con los no nacidos en tanto sujetos amenazados por el avance de propuestas legislativas criminales. Así, el lema "Salvemos las dos vidas" -bandera de los sectores conservadores - se presenta como un lenguaje político con una narrativa de amor orientada a estereotipar y construir una imagen social negativa del feminismo - "los pañuelos verdes"- como grupos de odio, identificados con la "cultura de la muerte". "Salvemos las dos vidas" es un eslógan antiderechos, mediante el cual la vulnerabilidad de los no nacidos es asociada a una idea de indefensión de la nación y de sus valores, y en el que la producción de un imaginario social de mujer como madre y reproductora por naturaleza y obligación busca anular las capacidades decisorias de los cuerpos gestantes.

Lo que se observa en el discurso político de los grupos antiderechos es una hibridación de narrativas religiosas, morales y científico-bioéticas que, en su entrelazamiento, hacen al lenguaje y a la identidad política del activismo antiabortista. La "vida" de los no nacidos es defendida como don y propiedad de Dios pero, al mismo tiempo, como una cuestión de derechos civiles avalados por el conocimiento científico. Los modos en que los grupos antiabortistas argumentan sus posturas desde criterios cientificistas y legales permiten entender las mutaciones lingüístico-discursivas del activismo 
religioso conservador y sus capacidades de adaptación a los debates sociopolíticos de las sociedades contemporáneas.

La incidencia que los autodenominados grupos "pro-vida" tienen en los debates políticos por la legalización del aborto es una demostración de cómo se va conformando, en las sociedades democráticas actuales, la trama de conflictividades que supone el agenciamiento de los derechos sexuales y (no)reproductivos. En este sentido, las intervenciones públicas y las movilizaciones callejeras que los grupos conservadores desarrollan, en orden a una regulación y disciplinamiento de la sexualidad, exigen su tratamiento y estudio como sujetos políticos de la dinámica democrática, así como la necesidad de romper con una visión sedimentada acerca de los actores religiosos como individuos relegados a la esfera de lo privado. Más bien, se trata de entenderlos como sujetos políticos que presionan y disputan, de modo constante, la traslación y conversión de sus principios dogmáticos como políticas de Estado y, en este sentido, el año 2019, en la Argentina, demuestra cómo el sello "pro-vida" apuntó a convertirse en una opción electoral antidemocrática vinculada a la defensa de valores tradicionales.

El aborto como problema de salud pública, que afecta tanto a la Argentina como a otros países de Latinoamérica, pone en evidencia las inconsistencias que existen entre la penalización de dicha práctica con relación a principios del sistema democrático como lo son la igualdad y los derechos de ciudadanía de las mujeres. Lo que predomina es una correlación y permeabilidad permanente de sentidos entre formas de control de la sexualidad y el cuerpo de las mujeres, y discursos sociales hegemónicos y dominantes - religiosos, biomédicos y jurídicos- que cuestionan el derecho al aborto como una práctica moral ilegítima. Los obstáculos que existen en torno al ejercicio de los derechos sexuales y (no)reproductivos ponen en cuestión aspectos que hacen al desarrollo de las libertades y los derechos de las mujeres, al mismo tiempo que reflejan las debilidades e insuficiencias del derecho y de las políticas de Estado en cuestiones competentes a la profundización de la laicidad. El problema del aborto remite a la importancia de analizar los alcances y limitaciones de la autonomía sexual y (no)reproductiva de las mujeres, teniendo en consideración los sentidos patriarcales y androcéntricos del derecho, las discrecionalidades existentes en el sistema público de salud y las formas en que dicha práctica es empujada a ser ejercida en condiciones asimétricas de desigualdad.

En resumen, los avances en términos de la dimensión legal y real de los derechos sexuales y (no)reproductivos quedan supeditados a la gravitación que sus fuerzas opositoras ejercen a nivel de lo político e institucional. La no separación Iglesia/ Estado y religión/política son ejes problemáticos que afectan a las sociedades latinoamericanas y a sus democracias. El activismo religioso conservador, enraizado en su articulación con el poder político, aboga por la profundización de leyes restrictivas sobre el aborto y la sexualidad, en tanto el principal desafío del movimiento feminista consiste en el desmontaje y la deconstrucción de una cultura patriarcal y misógina que se asienta en los mecanismos del derecho. Si bien los debates por la Ley de IVE fueron centrales y contribuyeron a reflotar las disputas por la laicidad del Estado y el derecho, el fracaso y la denegación de dicho proyecto confirma el peso que aún continúan ejerciendo los dogmas religiosos sobre los asuntos de la política y el devenir de los procesos institucionales. La construcción de sentidos criminales sobre el aborto es una estrategia cotidiana de los sectores conservadores para ejercer control y dominio sobre el cuerpo de las mujeres, mientras el sistema político, históricamente, ha resultado cómplice y partícipe de dicha afirmación. Para simplificar, las mujeres continúan sometidas a situaciones de inseguridad, de precariedad de derechos, de violencia y castigo punitivo, y el discurso pro-vida no solo las torna responsables de la reproducción de la vida sino que, además, las estereotipa como propagadoras de la muerte. 


\section{Referencias}

» Bergallo, P.; Jaramillo Sierra, I. C. y Vaggione, J. M. (comps.) (2018). El aborto en América Latina. Estrategias jurídicas para luchar por su legalización y enfrentar las resistencias conservadoras. Buenos Aires, Siglo XXI.

"Carbonelli, M. (2018). Los rostros políticos de los evangélicos en la Argentina reciente. En Revista Rupturas, pp. 61-83. Costa Rica, Centro de Investigación en Cultura y Desarrollo (CICDE), Universidad Estatal a Distancia.

»Deutscher, P. (2019). Crítica de la razón reproductiva. Los futuros de Foucault. Buenos Aires, Eterna Cadencia.

»Esquivel, J. C. y Vaggione, J. M. (comps.) (2015). Permeabilidades activas. Religión, política y sexualidad en la Argentina democrática. Buenos Aires, Biblos.

» Felitti, K. e Irrazábal, G. (2018). El Caso Belén y las construcciones sobre el no nacido en Argentina. Aportes para la discusión. En Revista de Bioética y Derecho, pp. 45-6o. Barcelona, Observatorio de Bioética y Derecho (OBD), Universidad de Barcelona.

" Gudiño Bessone, P. (2017). Activismo católico antiabortista en Argentina. Performances, discursos y prácticas. En Sexualidad, Salud y Sociedad. Revista Latinoamericana, pp. 38-67. Centro Latinoamericano en Sexualidad y Derechos Humanos (CLAM/IMS/UERJ).

»Héritier, F. (2007). Masculino/Femenino II. Disolver la Jerarquía. Buenos Aires, FCE. 